\title{
Sizing Optimization of Microactuaor In-plane Based on Ansys Workbench
}

\author{
Di Jie-jian ${ }^{1, a}$, Ren Sen ${ }^{1, b}$, Zhao Yu-xia ${ }^{1, c}$, Zhao Quan-liang $^{1, d}$, Tan Xiao-lan $^{1, e}$ \\ 1School of Mechanical and Materials Engineering, North China University of Technology, Beijing \\ 100041, China \\ adijiejian@ncut.edu.cn, ${ }^{\mathrm{b}}$ \\ 334671367@qq.com, 'czhaoyx@ncut.edu.cn, ${ }^{\mathrm{d}} z q \mathrm{l} @$ ncut.edu.cn, ${ }^{\mathrm{e}}$ tanxiaolan2004@126.com
}

Keywords: Microactuator; Ansys Workbench; Sizing Optimization

\begin{abstract}
One new type piezoeletric microactuator was designed in this paper, in order to improve the output characteristic of microactuator mechanism, piezoeletric analysis was performed and the optimization model was built with $w_{b}$ and $\alpha$ as design variables, the maximal output horizontal-plane displacement and the minimum vertical-plane displacement as objective. The final optimize result shows that the output horizontal-plane displacement of microactuator raises twice from $0.3 \mu \mathrm{m}$ to $0.6 \mu \mathrm{m}$, meanwhile, the output vertical-displacement decreases from $0.093 \mu \mathrm{m}$ to $0.075 \mu \mathrm{m}$ by approximately 21 percent, the horizontal output characteristic has a remarkable improvement, so the optimal result can provide validity theoritical guidance for coming design strategy.
\end{abstract}

\section{Introduction}

Microactuator's function is to provide force or diaplacement output, it can transform other energy types such as electric energy, light energy, thermal energy into mechanical energy, so it has multiple different working principles and structural forms. Micro-electro-mechanical system(MEMS) consists of microactuator, microsensor, signal processing, control circuit, as the power source, microactuator plays an important role in micro-electro-mechanical system, its performance index directly impact devices' operational capability and efficiency, so it's important to obtain better output characteristic by optimizing sizes of microactuator. Piezoelectric microactuator has salient advantages such as it can produce large output force or displacement, quick response speed, high working frequency and control precision, etc ${ }^{[1,2]}$, so piezoelectric actuation is an ideal way to produce micro displacement, it has a great application potential in the future.

In this paper one new type piezoelectric microactuator with displacement magnification function was designed, the simple structure can be widely used in the internet things system to sense and drive.

\section{Working Principle and Geometric Model of the Microactuator}

The symmetrical structure of the microactuator is shown in Fig.1, it mainly consist of three parts, named as fixed port, central double-layer beam surrounded with rigid beam, and driving end. The upper layer of double-layer structure is piezoelectric membrane and the lower layer is made up of silicon, the elastic modulus and poisson ratio of silicon is respectively 179Gpa and 0.3. Size parameters of the microactuator are listed in table 1.

Based on the inverse piezoelectric effect, the working principle of the microactuator in horizontal-plane is once the positive and negative voltages is respectively applied on the bottom surface and the top surface, the central beam will bend up and down, and the deformation in plane will be produced in $\mathrm{x}$ direction, and the movement would be produced in y direction of rigid beam, thus driving displacement in plane would be produced. To improve the output displacement of the driving end in plane, the sizing optimization design ${ }^{[3-6]}$ is performed with the software ANSYS Workbench. 


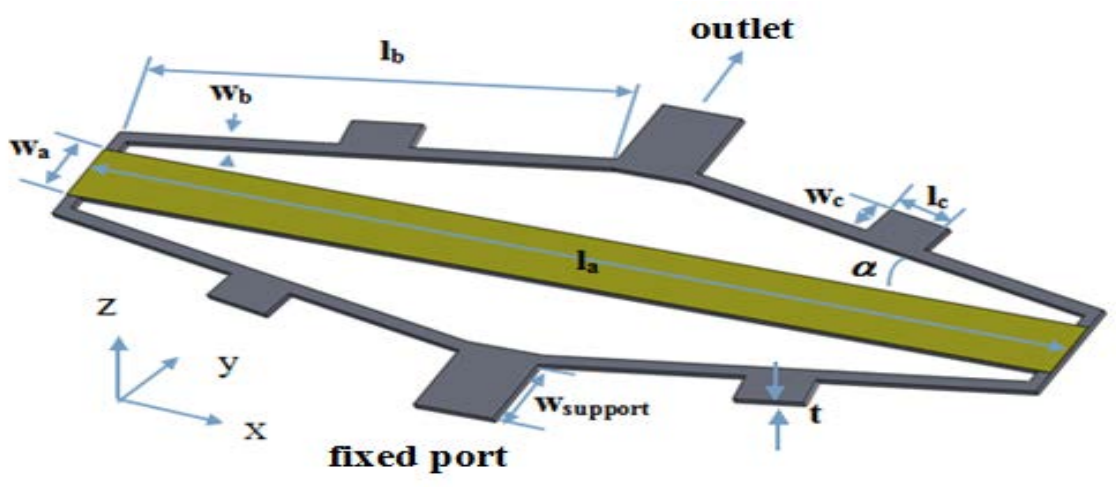

Fig.1 Geometric structure of the microactuator Table1.Main parameters of the microactuator

\begin{tabular}{ccccccccc}
\hline Parameters & $\begin{array}{c}l_{a} \\
{[\mu \mathrm{m}]}\end{array}$ & $\begin{array}{c}w_{a} \\
{[\mu \mathrm{m}]}\end{array}$ & $\begin{array}{c}l_{b} \\
{[\mu \mathrm{m}]}\end{array}$ & $\begin{array}{c}w_{b} \\
{[\mu \mathrm{m}]}\end{array}$ & $\begin{array}{c}l_{c} \\
{[\mu \mathrm{m}]}\end{array}$ & $\begin{array}{c}w_{c} \\
{[\mu \mathrm{m}]}\end{array}$ & $\begin{array}{c}w_{\text {support }} \\
{[\mu \mathrm{m}]}\end{array}$ & $\begin{array}{c}\alpha \\
{\left[{ }^{\circ}\right]}\end{array}$ \\
{$[\mu \mathrm{m}]$}
\end{tabular}

\section{Optimal Design of the Microactuator}

\subsection{Initial Design Simulation of the Microactuator}

FEM model of the microactuator is shown in Fig.2, the fixed port is constrained, the forces with the magnitude 7.26E-3N are applied on both sides of the central beam. The deformation in $\mathrm{y}$-direction and z-direction of the microactuator is respectively shown in Fig.3 and Fig.4, it is shown that the largest deformation in $y$-direction happens at the driving end and the largest deformation in $\mathrm{z}$-direction happens at the both ends of the microactuator, and the displacement of the driving end in $\mathrm{y}$-direction and z-direction is repectively $0.3 \mu \mathrm{m}$ and $-0.093 \mu \mathrm{m}$.
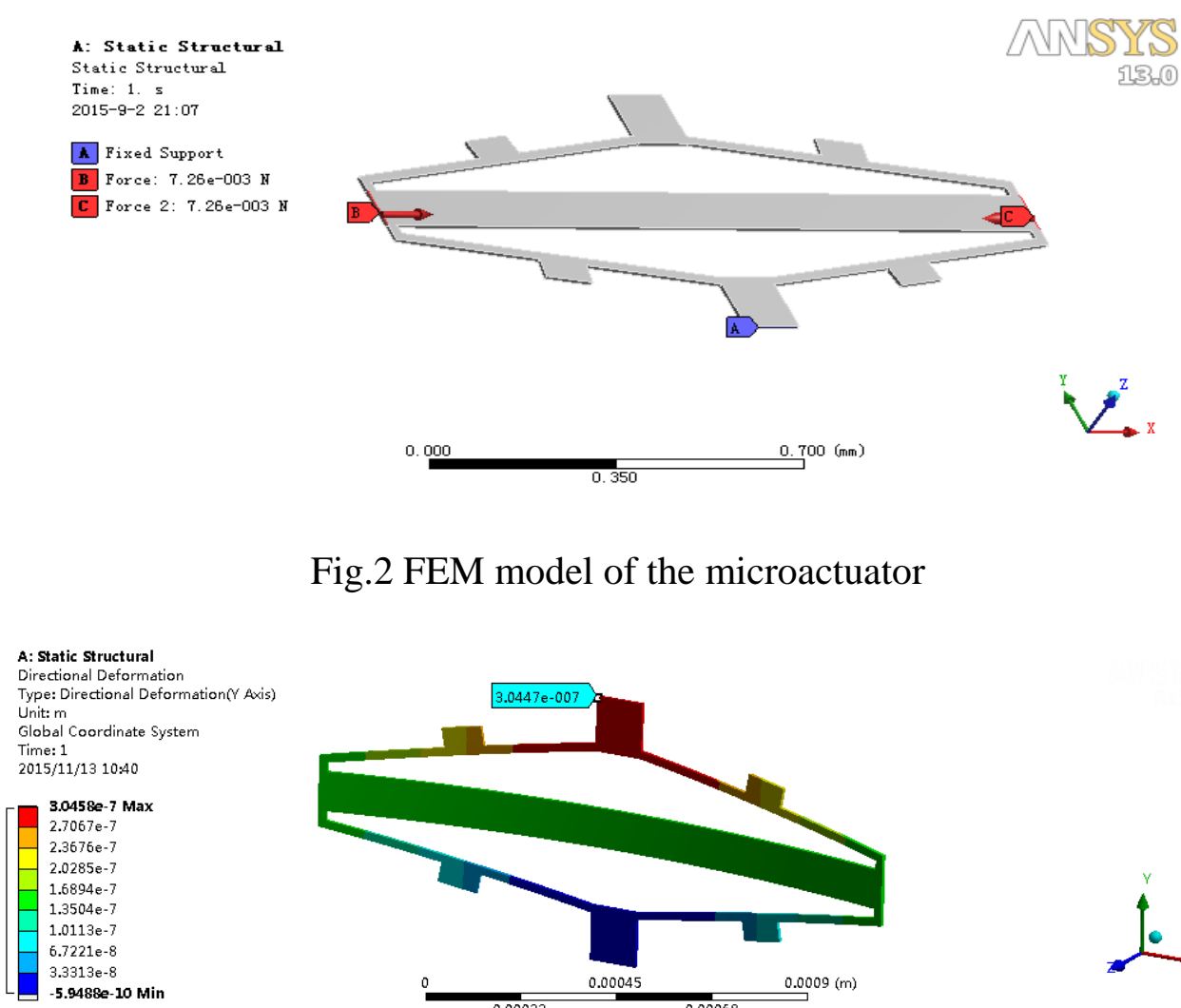

Fig.2 FEM model of the microactuator
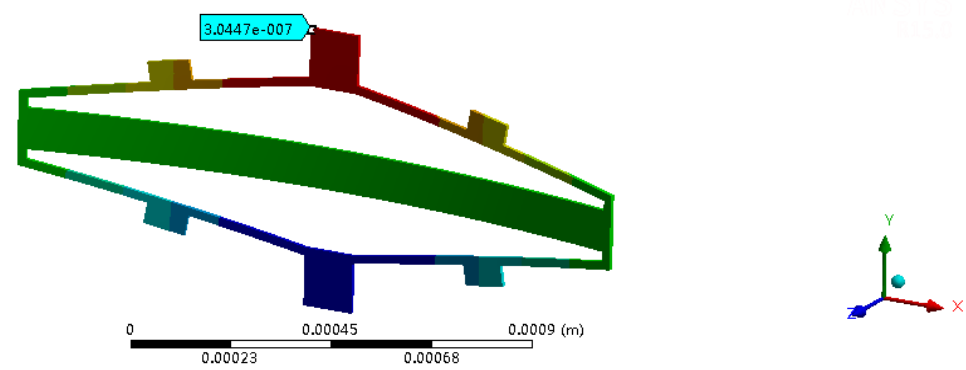

Fig.3 Y-direction displacement of microactuator 

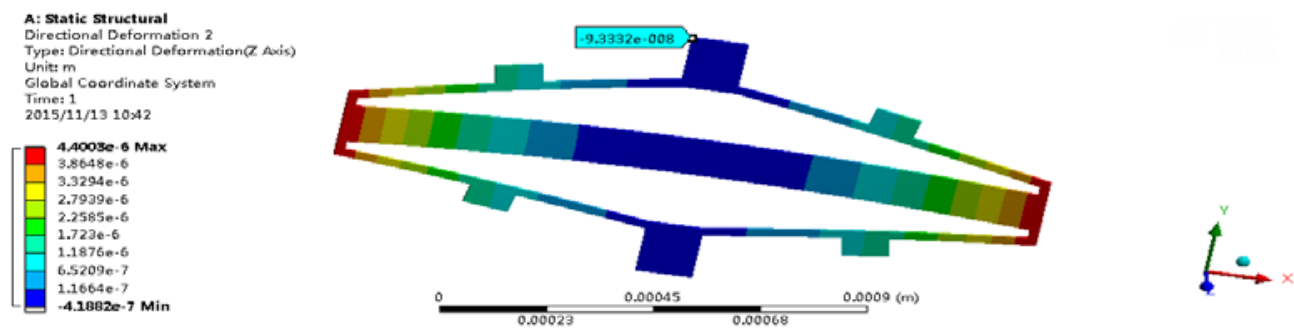

Fig.4 Z-direction displacement of microactuator

\subsection{Mathematical Optimization Model of the Microactuator}

The role of the microactuator is to provide as large y-diretion displacement as possible, and an overlarge z-diretion displacement has a seriously adverse effect on the horizontal output characteristic of the microactuator, so the capability to provide y-direction displacement in the driving end is the most important indicator of the microactuator, thus, the maximum output $\mathrm{y}$-diretion displacement should be chosen as the objective, in addition, the z-direction displacement of the driving end should be as minimal as possible to keep the functional planarity. A multi-objective model is built to obtain maximum y-direction displacement and minimum z-direction displacement on the driving end of the microactuator. The optimization numerical model is shown below:

$$
\left\{\begin{array}{cl}
\max & u_{y}\left(w_{b}, \alpha\right) \\
\min & \left|u_{z}\left(w_{b}, \alpha\right)\right| \\
\text { s.t. } & w_{b l} \leq w_{b} \leq w_{b u p} \\
& \alpha_{l} \leq \alpha \leq \alpha_{u p}
\end{array}\right.
$$

Where:

$u_{\mathrm{y}}-\mathrm{y}$-direction displacement of the driving end

$u_{\mathrm{z}}-\mathrm{z}$-direction displacement of the driving end

$w_{b}$ - the width of the rigid beams

$\alpha$ - the angle between the rigid beams and the central beam

$w_{\mathrm{bl}}, w_{\mathrm{bup}}-$ the lower and upper limit of the design variables

$\alpha_{l}, \alpha_{u p}-$ the lower and upper limit of the design variables

\subsection{Sensitivity Analysis and Optimization}

The sensitivity analysis is performed with the design variable $w_{b}$ and $\alpha$ respectively belonging to $10 \sim 30 \mu \mathrm{m}$ and $0.1^{\circ} \sim 5^{\circ}$. The 25 groups of design points are automatically generated with the method of Central Composite Design in ANSYS Workbench, the sensitivity analysis result is shown in Fig.5, it can be concluded that the angle between the rigid beams and the central beam $(\alpha)$ has a greater effect on the displacement in y-direction and z-direction of the driving end, in addition, the width of the rigid beams $\left(w_{b}\right)$ has a comparatively less effect on displacement in both of y-direction and z-direction of the driving end. The structural response cuve (Fig.6) is extracted, and the relationship between the output displacements and design variables can be seen from it.

As shown in Fig.6(a), the output displacement in y-direction increases with the angle $\alpha$ increasing from zero to $5^{\circ}$, and then decreases with $\alpha$ increasing, the maximum value happens at the point with angle about $5^{\circ}$. From the Fig.6(b), it is shown that the minimum displacement of $u_{z}$ happens at the point with angle about $16^{\circ}$, the z-diretion displacement value reduces to 0 approximately with the angle $16^{\circ}$. It can be seen from the Fig.6 (c) and (d) that the displacements of $u_{\mathrm{y}}$ and $u_{\mathrm{z}}$ decrease with $w_{\mathrm{b}}$ increasing, it is due to the stiffness of the structure is increased with $w_{\mathrm{b}}$ increasing. 


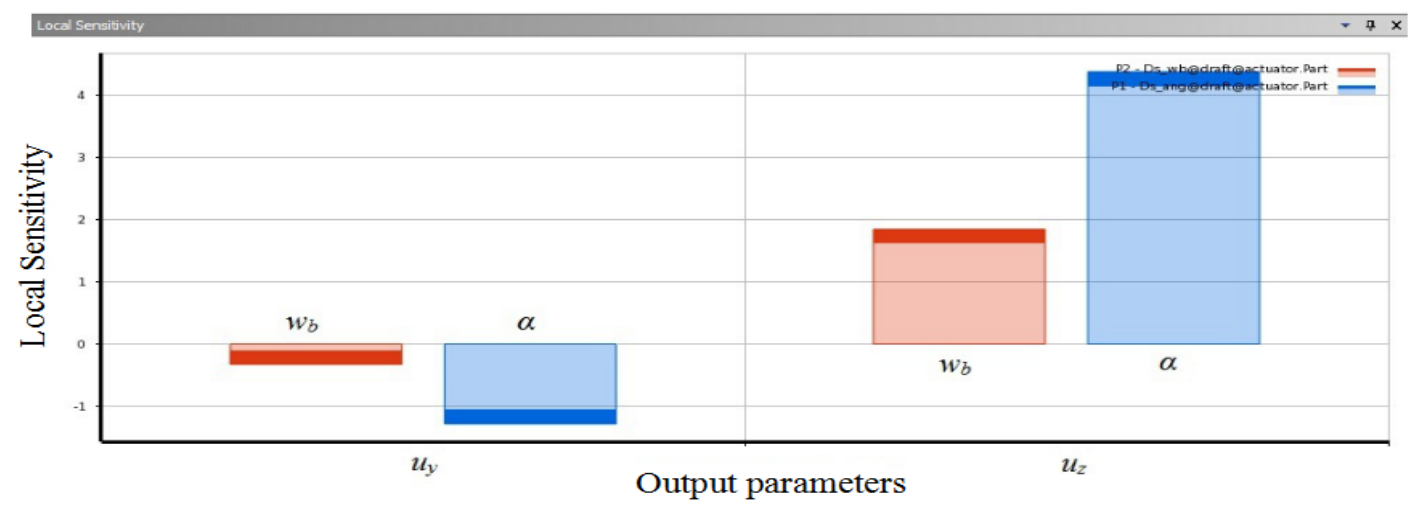

Fig.5 Sensitivity analysis histogram

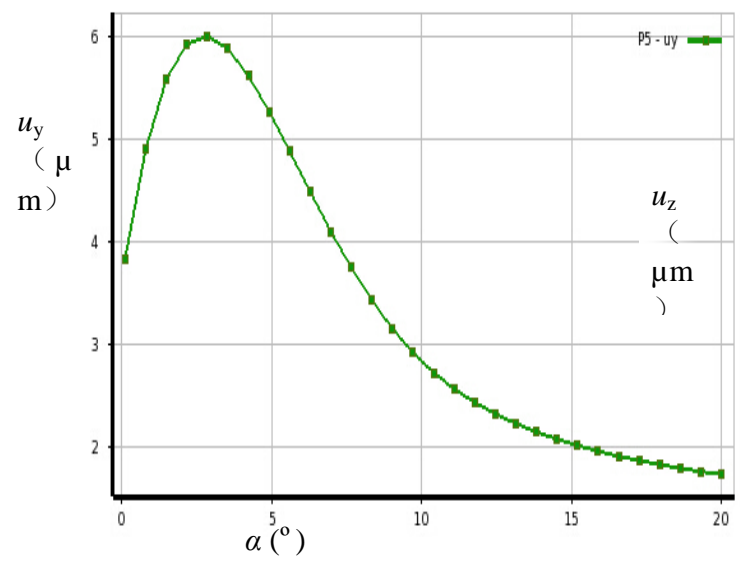

(a) Relationship between $\alpha$ and $u_{y}$

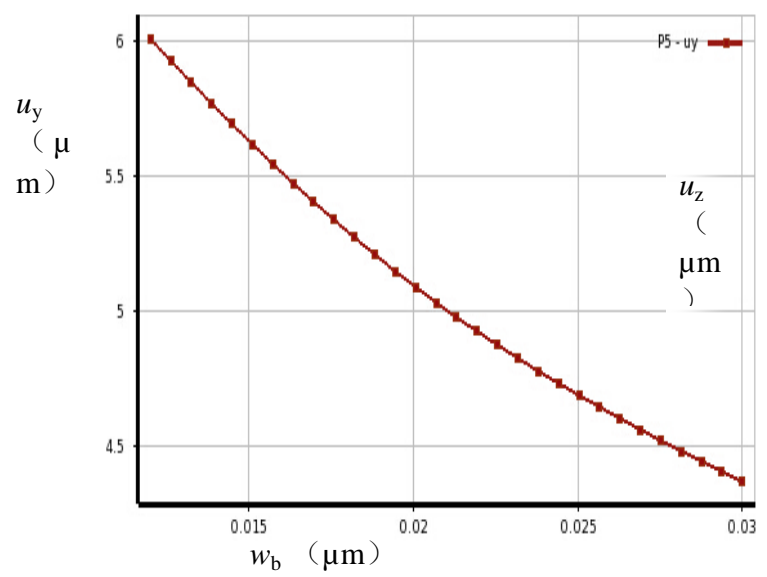

(c) Relationship between $w_{\mathrm{b}}$ and $u_{y}$

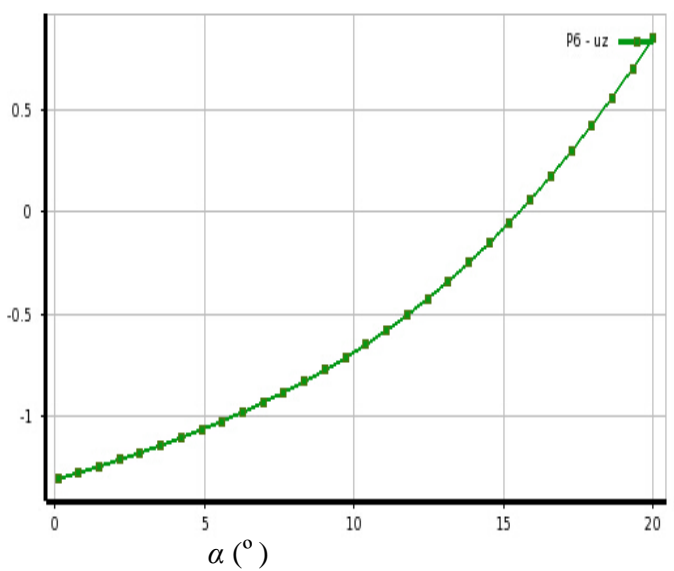

(b) Relationship between $\alpha$ and $u_{z}$

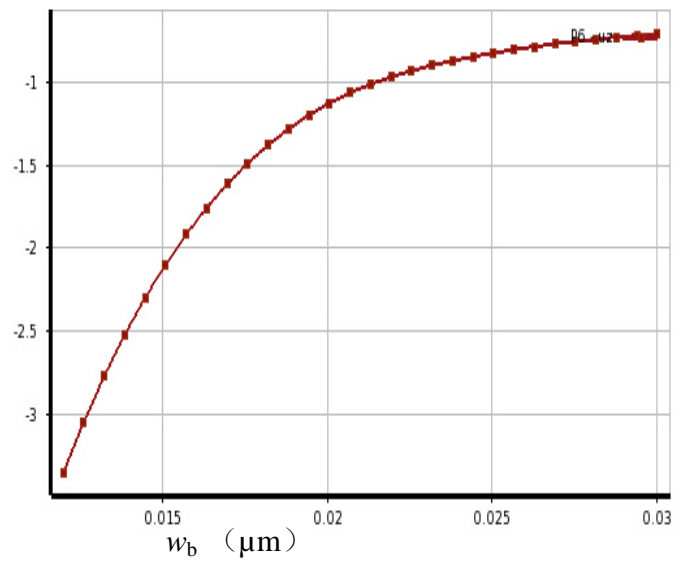

(d) Relationship between $w_{\mathrm{b}}$ and $u_{z}$

Fig.6 The relationship between the output displacements and design variables

The optimization model is solved with DOE method (Design of Experiment), with the maximum displacement in y-direction, the minimum absolute value of output displacement in z-direction $\left|u_{z}\right|$ chosen as objectives, three final candidate results are listed in table 2. Compared with the original design result, the displacement of the driving end in y-direction has a remarkable improvement from $0.3 \mu \mathrm{m}$ to $0.72 \mu \mathrm{m}$ by about 140 percent in the optimal design 1 , however, the displacement of the driving end in z-direction is also raised significantly from $0.093 \mu \mathrm{m}$ to $0.14 \mu \mathrm{m}$ by about 47.4 percent. From the optimal design 2, it is shown that the displacement in y-direction increases remarkably from $0.3 \mu \mathrm{m}$ to $0.6 \mu \mathrm{m}$ by about twice and the displacement in z direction decreasing from $0.093 \mu \mathrm{m}$ to $0.075 \mu \mathrm{m}$ at the same time, the result of optimal design 3 shows that the displacement in y-direction has a less improvement. For the optimal design 2 in table 2, by comparing with the results of optimal design 1 and 3, it has a better horizontal output characteristic, so the optimal result is fairly good. Consequently, the design variables parameters of optimal design 2 in table 2 can be chosen as the final optimal design combination of the microactuator. The angle value between the rigid beams and the central beam $(\alpha)$ should be chosen $4.2^{\circ}$ and the width value of the rigid beams 
$\left(w_{b}\right)$ should be chosen $19 \mu \mathrm{m}$.

Table.2 Comparison of optimal design with original design

\begin{tabular}{|c|c|c|c|c|c|c|}
\hline & $\alpha\left[^{0}\right]$ & $w_{b}[\mu \mathrm{m}]$ & $u_{y}[\mu \mathrm{m}]$ & $\left|u_{z}\right|[\mu \mathrm{m}]$ & $u_{y} \quad$ variation & $\left|u_{z}\right|$ variation \\
\hline Original design & 10 & 20 & 0.3 & 0.093 & & \\
\hline Optimal design 1 & 2.2 & 16.7 & 0.72 & 0.14 & $140 \%$ increase & $47.4 \%$ increase \\
\hline Optimal design 2 & 4.2 & 19 & 0.6 & 0.075 & $100 \%$ increase & $21 \%$ decrease \\
\hline Optimal design 3 & 6.1 & 19.2 & 0.47 & 0.07 & $56.7 \%$ increase & $26.3 \%$ decrease \\
\hline
\end{tabular}

\section{Conclusions}

To acquire the maximum displacement in y-direction and minimum displacement in z-direction, the optimization technology is used. The multi-objectve optimization model is built with the width $w_{b}$ of the rigid beams, and the angle $\alpha$ between the rigid beams and the central beam as design variables. The sensitivity analysis and optimization are performed. Results show that the displacement in y direction and $\mathrm{z}$ direction is greatly affected by width $w_{b}$ and the angle $\alpha$, the optimal displacement in y direction doubles the original design from $0.3 \mu \mathrm{m}$ to $0.6 \mu \mathrm{m}$, meanwhile the displacement in z direction decreases from $0.093 \mu \mathrm{m}$ to $0.075 \mu \mathrm{m}$. The optimization method is proved effective and has a certain instructional significance to engineering design.

\section{Acknowledgements}

This project was supported by Sceientific Research Common Program of Beijing Municipal Commission of Education under Grant no. KM201410009001, the National Natural Science Foudation of China Grant nos. 51305005, 51375016 and 51402005, Beijing Natural Science Foudation under Grant no. 3122013.

\section{References}

[1] Gong Feng-fei:The Princple and Application of Microactuators[J]. Electronic Component and Materials, 2007(6):33-36.

[2] Liang Lei, Wang Shao-ping: The Research and Development of Microactuators[J]. Machinery Design and Manufacture. 2008 (7) : 227-229.

[3] Stephane Vivier, Didier Lemoine: Fast Optimization of a Linear Actuator bySpace. Transacti-ons on industry applications.2011:2059-2065.

[4] V. Behjat, A. Vahedi: Analysis and optimization of MEMS Electrostatic Microactuator [J]. MEMSTECH, 2007: 23-26 .

[5] Mohsen Nabipoor: Dimension Optimization of a MEMS LC pressure sensor.ICSE, 2008:148-152.

[6] Attilio Frangi, Massimiliano Cremones: On the optimization of piezoelectrically actuated MEMS resonators. International Ultrosonics Symposium Proceedings, 2012: 1043-1046. 